\title{
Akıllı Mutfak İçin Tasarlanmış Sistemler Üzerine Bir Derleme
}

\author{
A Review on Systems Designed for the Smart Kitchen
}

\author{
Zehra K. KÜÇÜK ${ }^{1}$ (D), Nazmi EKREN ${ }^{2}$ \\ ${ }^{1}$ Marmara Üniversitesi, Fen Bilimleri Enstitüsü, Elektrik Elektronik Mühendisliği ABD, 34722, Göztepe Kampüsü, \\ Kadlköy, İstanbul \\ ${ }^{2}$ Marmara Üniversitesi, Teknoloji Fakültesi, Elektrik Elektronik Mühendisliği Bölümü, 34722, Göztepe Kampüsü, Kadıköy, \\ Istanbul
}

$\ddot{O} \mathbf{z}$

Günümüzde hızla gelişen teknoloji ile birlikte birçok yenilik de hayatımıza girmiş bulunmaktadır. Bunların başında ise hayatımızı kolaylaştıran çeşitli akıllı sistemler gelmektedir. Yaşamımızın her alanına uyarlanabilen bu sistemlerde amaç hayatı kolaylaştırmanın yanı sıra enerjiyi etkin kullanmaktır. Nesnelerin interneti ile de entegre edilmiş ve iyi tasarlanmış akıllı bir sistem her açıdan kullanıcı konforuna hizmet etmektedir. Her birey ve ortam için uygun nitelikte tasarlanmış çalışmalar yaygın şekilde görülmeye başlanmıştır. Bu çalışmada ise akıllı ev kavramından yola çıkılarak, çeşitli senaryolara dayanarak üretilmiş ve birçok ek sistemle desteklenmiş güncel akıllı mutfak tasarımları incelenmiştir. İncelenen çalışmalarda da görüleceği üzere akıllı olmayan bir sisteme kıyasla enerji, zaman ve konfor gibi öğeler göz önüne alındığında akıllı bir sistemi tercih etmek her zaman daha mantıklı hale gelmiştir.

Anahtar kelimeler: akıllı mutfak, buzdolab1, akıllı bina, enerji tasarrufu, nesnelerin interneti, makine öğrenmesi, yapay zeka, zaman tasarrufu

\begin{abstract}
Today, with the rapidly developing technology, many innovations have entered our lives. The first of these is the various systems that make our life easier. These systems can be adapted to any area of our lives. The purpose of these systems is to use energy effectively as well as making life easier. If the system is well designed and integrated with the internet of things, it serves user comfort in every respect. Studies designed for each individual and environment have started to be widely seen. In this study, the concept of smart home was started and contemporary smart kitchen designs that are produced based on various scenarios and supported by many additional systems are examined. Given the elements such as energy, time and comfort, it has always been more logical to choose a smart system. This is also seen in the studies examined.
\end{abstract}

Keywords: smart kitchen, refrigerator, smart building, energy saving, internet of things, machine learning, artificial intelligence, time saving

\section{Gİiş̧}

Akıllı bina sistemleri, kontrol edilmek istenilen sisteme ait verilerin alınıp gerekli değerlendirmelerin yapılarak istenilen çıktıların elde edilmesi sistemi şeklinde tanımlanabilir. Bu sistemlerde temel kriter, etkin enerji kullanımı ile optimum fayda sağlamaktır. Binalarda; iklimlendirme, aydınlatma, yangın önleme, alarm, dış cephe ve çatı, güvenlik gibi birçok konuda akıllı bir sistem kurulabilir. Daha alt sistemler düşünüldüğünde; eğlence, sağlık, bebek ve hayvan görüntüleme, bahçe işleri, eğitim vb. amaçlarla bina içinde daha spesifik alanlara uygun sistemler tasarlanıp entegre edilebilmektedir. Burada temel amaç kullanıcı konforu sağlayıp hayatı kolaylaştırmaktır. Günümüzde sürdürülebilir enerji, kullanıcı konforu ve zaman tasarrufu oldukça önemlidir. Özellikle alışveriş merkezi, okul, hastane, ofis binaları gibi toplu ve çok kullanılan alanlarda akıllı sistemlerin kullanılması daha etkin olmaktadır. Artık hayatımızın her alanına girmiş bulunan 'nesnelerin interneti (IoT: internet of things)' sayesinde ise akıllı bir sistem tasarlamak daha da kolaylaşmıştır. Kontrol mekanizması genellikle 
çeşitli sensörlere bağlıdır. Sensörlerden alınan veriler sayesinde kontrol edilmek istenilen nesnenin, ortamın veya çevrenin bilgisi alınmış olur ve gerekli değerlendirmeler yapılarak gerekli çıktılar sağlanır. Alınan çıktılar sayesinde sistem istenilen şekilde ve doğrultuda kontrol edilebilmektedir. $\mathrm{Bu}$ mekanizmalar kullanıcıya mekandan bağımsız bir şekilde kontrol imkanı sunarak kullanılabilirliği artırmaktadır.

Akıllı evler ise bireysel anlamda hayatı kolaylaştıran, enerjiden ve zamandan tasarruf sağlayan, insan güvenliği ve konforunu amaçlayan akıllı bina sistemleri kapsamında yer almaktadır. Bir annenin bebeğiyle alakalı durumları kontrol etmesinden bir yaşlının evdeki durumları kontrol etmesine varıncaya kadar sayısız senaryoya bağlı olarak çeşitli tasarımlar yapılabilmektedir. Bütün bunlara ek olarak sistem, yapay zekâ, artırılmış gerçeklik, makine öğrenmesi ile de desteklendiğinde düşük hata oranıyla çalışan, enerji etkin, kullanıcı konforlu, güvenli bir sistem elde edilmiş olmaktadır. Mutfak, ev içi üretimin ve tüketimin merkezi olduğu için oldukça önemli bir mekandır. Hem enerji ve zaman tasarrufu açısından hem israfın önüne geçilmesi açısından akıllı bir sistem ile entegre edilmiş bir mutfak insan hayatında gereklilik kazanmıştır. Ayrıca çeşitli hastalıkları olan veya engelli bireylerin yaşam kalitelerini artırmak için yardımcı sistemler şeklinde tasarlanmış sistemler mutfaklara entegre edilebilmektedir. Tüm bunların yanı sıra mutfakta meydana gelebilecek yangın, gaz kaçağı gibi olağan dışı durumlar için çeşitli senaryolar üretilerek tedbir ve güvenlik sağlayacak sistemlere de ihtiyaç duyulmaktadır. Günümüzde insan gereksinimlerini karşılama ve konforunu sağlamayı merkez alarak yapılmış enerji etkin, çevreci, kullanışlı birçok akıllı mutfak sistemi mevcuttur. Son yıllarda teknoloji hizla geliştiği, yenilikler hayatımıza hızla girdiği için bu makalede özellikle son yıllarda yapılan akıllı mutfak odaklı çalışmalar incelenerek güncel gelişmeler değerlendirilmiştir.

\section{AKILLI MUTFAKLA İLGILİ SON GELISSTMELER}

Güncel akıllı mutfak çalışmaları, günümüz teknolojisi ve insan gereksinimleri doğrultusunda, mutfağın ve mutfakta bulunan materyallerin uzaktan/yakından erişilerek kontrol edilebilmesini sağlamak, mutfakta meydana gelen olağan dışı durumlara müdahale edilebilmesini sağlamak ve akıllı sistemlere ek çeşitli sistemler ile konforu artırmak gibi birçok amaçlarla yapılmıştır.

\subsection{Envanter Kontrollü Sistemler}

Rezwan S. ve ark. [1], IoT’ye dayanan, mutfak, ilaç, restoran envanterini yönetmeyi daha verimli ve sorunsuz hale getirecek bir sistem olan akıllı mutfak envanter yönetim sistemi (Smart kitchen inventory management system: SIMS) önermişlerdir. Önerilen sistemi simüle etmek için farklı sensörlerle birleştirilmiş dokuz bölme içeren küçük bir prototip kabin üretmişlerdir (Şekil 1). Bu sistem, yalnızca mevcut envanterlerini kullanıcılara bildirmekle kalmaz, aynı zamanda miktar azalırsa yeni ürünler için otomatik olarak sipariş verir. Kullanıcılar, doğrudan SIMS uygulamalarından herhangi bir malzemeyi almak için çevrimiçi sipariş verebilirler. Ayrıca kullanıcı belirli bir zaman dilimi listesi oluşturabilir, böylece harcamaları hakkında bilgi sahibi olur. Buna ek olarak, kullanıcı sipariş durumunu ve sipariş geçmişini web sitesi üzerinden takip edebilir. Son olarak, "SIMS'in bir parçası olan Akıllı Mutfak Envanteri (Smart Kitchen Inventory: SKI, mevcut yiyeceklerin gerçek zamanlı verilerini toplayan ve veritabanına gönderen bir yazılıma sahip) sayesinde, insanlar web sitesi veya android uygulaması arac1lığıyla her yerden çalıştırılabilecekleri ve istedikleri zaman istedikleri her şeyi sipariş edebilecekleri için market alışverişinin zorluklarını unutabilirler" şeklinde bir ifadede bulunmuşlardır. Buzzelli M. ve ark. [2], evrişimsel sinir ağlarına dayalı, sebze ve meyve tanıması için en son teknolojiyi sunduklarını belirtmişlerdir. Önerilerini, yerleşik kameralar ile donatılmış akıllı mutfak/buzdolabı konsepti üzerine geliştirmişlerdir. Bu amaçla, tasvir edilen (görüntülenen) malzemelerin sınıfına (meyve, sebze gibi özellikler) göre özel olarak gruplandırılan ve adlandırılan bir veri kümesi oluşturmuşlardır. İki tür deney gerçekleştirmişlerdir: ilk olarak, son teknolojiye sahip farklı nöral mimarileri sebze ve meyve tanıma görevinde eğitmiş ve değerlendirmişlerdir. İkinci olarak, sistemlerinin nihai performansını daha da geliştirmek için bu tür sınıfların hiyerarşik yapısından yararlanan bir test düzeneği tasarlamış ve test etmişlerdir. Deneysel sonuçların, mevcut çözümlere kıyasla önerilen çözümün nicel üstünlüğünü gösterdiğini belirtmişlerdir. Jian-mei S. ve ark. [3], makalelerinde sensör, ZigBee, gömülü sistem, veritabanı, Web uygulaması, Android mobil geliştirme vb. gibi çeşitli teknolojileri entegre eden bir tür akıllı mutfak yönetim sistemi önermişlerdir. Çalışma, sistem yapısını, sistem fonksiyonunu, tasarım planını ve sistemin uygulanmasını tanıtmaktadır. Akıllı mutfak sistemi dört bölümden oluşur, birincisi mutfağın bilgi algılama alt sistemi; ikincisi, alg1lama altsisteminden bilgi alan ve daha fazlasını sunucuya ileten mutfağın ağ geçidi sistemidir; üçüncüsü, mutfak bilgilerini depolamak ve işlemek, algı ve mobil terminallerle iletişim sağlamak için kullanılan Web sunucusudur. Sonuncusu, uzaktan kumandayı gerçekleştiren ve mutfak bilgilerini kontrol eden mobil terminal alt sistemidir. Önerilen sistemin iyi uygulanabilirliği ve genişletilebilirliği olduğunu ve insanların yaşamlarının akıllıık seviyesini artırdığını belirtmişlerdir. Jarupunphol P. ve ark. [4], çalışmalarında, habersiz ve örgütlenmemiş şekilde satın alınan mutfak eşyalarının/ 
bileşenlerinin alımını azaltmak amacıyla akıllı mutfak yönetimi (smart kitchen management: SKM) için bir mobil uygulama tasarlamışlardır. SKM sisteminde iki ana aktör vardır: yönetici ve kullanıcı. Yönetici, QR kod üretir ve mutfak bileşenlerinin detaylarını (isim, resim, birim ve QR kod (Quick Response Code)) veri tabanına ekler. Kullanıcı, QR kod kullanılarak sisteme tanımlanan ürünleri ekleyebilir, silebilir ve değiştirebilir. UML (Unified Modeling Language: Birleşik Modelleme Dili) ve Z şemaları, sistemle ilişkili durumları temsil etmek için tasarım sürecinde kullanılmıştır. SKM durum şemasında ve işlem şemasında tanımlanan mantıksal argümanlar, SKM'nin nasıl tasarlanması gerektiğgine ilişkin temel kuralları göstermektedir. SKM ayrıca, SKM'nin dört kullanılabilirlik boyutunu (yani, kullanışlılık, kullanım kolaylığı, öğrenme kolaylığı ve memnuniyet) ölçmek için USE Anketinden uyarlanan soruları içeren anket 180 katılımcı ile denenmiştir. Deneysel sonuçlar uygulamanın düzgün çal1şabileceğini ve mutfak eşyalarının/malzemelerinin gereksiz satın alma sayısını ele alma potansiyeline sahip olduğunu ve ayrıca bu ürünlerin/malzemelerin önemine göre öncelik verdiğini göstermiştir. Arya A. ve ark. [5], çalışmalarında mutfak bileşenlerinin ölçümlerini yeni ve çekici bir tasarımla akıllı bir şekilde ele almaktadır ve bu tasarım herhangi bir zamanda bir android uygulaması veya web sitesi tarafindan kontrol edilebilmektedir. Sistemdeki sensörler, bileşenlerin miktarını hesaplamak için kullanılır ve raspberry pi ile kontrol edilir. Burada miktar ölçmek için kullanılan sensör ağırlık sensörü değil ışık sensörüdür. Ayrıca sistem, bileşen seviyesini belirli zamanlarda kontrol ederek yakındaki mağazalardan sipariş vermektir. Bunlara ek olarak mutfaktaki ışıklar da kullanıcıya göre 1sı sensörü ile kontrol edilmektedir. Bu tasarımın herkes için uygun fiyatlı bir tasarım olduğunu belirtmişlerdir. Çalışmalarıyla Digital India'ya da katkıda bulunmayı amaçlamışlardır.
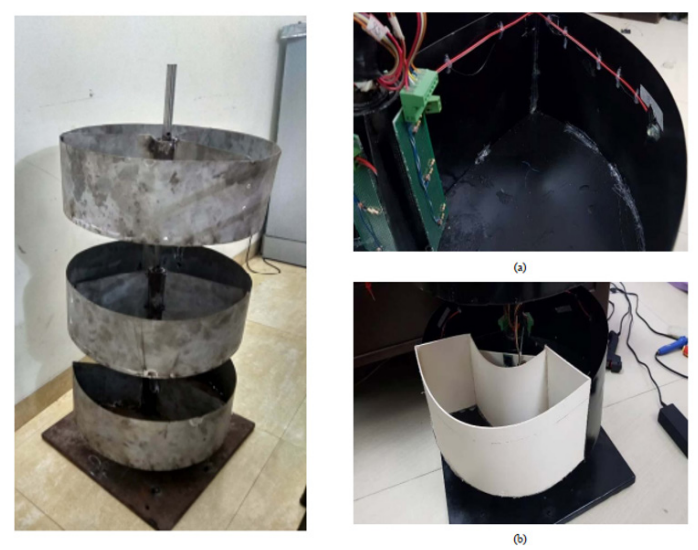

Şekil 1. SKI kabini resmi a) LDR/LED (Light Dependent Resistor/ Light Emitting Diode) sensörü ile seviye ölçümü b) ağırlık ölçümü [1]

\subsection{Yemek Pişirme Temelli Sistemler}

Sasirekha S. ve ark. [6], bugün en önemli sorunlardan birinin mutfakta birçok malzemeye sahip olmak, ancak ne pişireceğini bilmemek olduğunu belirtmişlerdir. Makalelerinde esas olarak mutfakta bulunan gida maddelerine göre uygun tarifler öneren bir sistem tasarlamışlardır. Her yiyecek maddesi Radyo Frekansı Tanımlama (Radio-Frequency Identification: RFID) etiketi kullanılarak etiketlenir ve bir RFID kart okuyucu kullanılarak taranır. Taranan öğelere bağlı olarak, bu uygulama belirli bir zamanda mevcut gida maddelerinden pişirilebilecek tariflerin bir listesini önerir. Önerilen makale API (Application Programming Interfaces) merkezlidir. API'lar arasındaki etkileşim RESTful (Representational State Transfer) web servisleri aracıllğıyla sağlanmıştır. Kullanılan bu arayüzlerin ve haberleşme kaynaklarının kullanışl1lığ dolayısıyla kolayca genişletilebilirlik sağlayan, akıllı mutfak için kullanılan API'leri akıllı sağlık gibi diğer benzer uygulamalara da geliştirmeyi amaçlamışlardır. Çelik ve ark. [7], 'Choptop' adını verdikleri, deneyimsiz aşçılar için uygun; basit; tarif kılavuzu, uygun tartım ve zamanlama araçları içeren; etkileşimli bir doğrama tahtası önermişlerdir. Bu asistanın, özellikle yemek yapmayı öğrenmek için sınırlı zamanı olan ve bu nedenle yüksek fiyatlı ve sağlıksız alternatiflere yönelen öğrenciler gibi bireyler için yararlı olduğunu belirtmişlerdir. Choptop'un ekranında, kolayca zarar görebilen tarif kitapları ve mobil cihazlara olan ihtiyacı ortadan kaldıran adım adım talimatlar içeren tarif klavuzu görünür. Kullanıcılar yük sensörleri ile çalışan doğrama yüzeyine basarak Choptop’ta dolaşırlar(Şekil 2). Ayrıca tartım yapabilme özelliğine sahiptir. Yapılan testler, Choptop'un geleneksel yöntemlere göre çeşitli tariflerin kolaylığını ve doğruluğunu önemli ölçüde artırabildiğini göstermiştir. Kullanıcılar ayrıca karmaşık tarifleri takip ederken daha fazla keyif aldıklarını bildirmişlerdir. Sharath B. ve ark. [8], yemekleri kullanıcı zevkine göre pişiren otonom pişirme cihazının uygulama mekanizmaları hakkında bir çalışma yapmışlar, istenen yemekleri pişiren özerk bir pişirme sistemi tasarlamışlardır. Sistem: robot mekanizması, ısıtma mekanizması, pişirme mekanizması, öngörülü yapay zeka algoritması ve Android'den oluşmaktadır. Pişirme mekanizması, yapay zeka ve geleneksel sinir ağı eğitim algoritmaları kullanılarak farklı kullanıcılar için özelleştirilmiştir. Cihaz, günümüz yemeklerinde kullanılan ayrı cihazların aksine, tek bir cihaza gömülü kızartma, pişirme, çalkalama uygulamalarına sahiptir. Uygulama prototipi sebze ve sıvı bileşenleri içeren dokuz farklı bileşeni desteklemektedir. Kullanıcının tek sorumluluğu malzemeleri sistem tarafından belirtilen s1rayla ve miktarda doldurmaktır. Sistem bulut bilgisayar ve yerel sürücülerle kontrol edilmektedir. Bu sistemin kullanıcılara sağlıklı, temiz ve besleyici gıdalar sağladığını ayrıca 
düşük torklu de motorları ve de servo motorları sayesinde düşük maliyetli olduğunu belirtmişlerdir. Ayrıca yazılımın, kullanıcının pişirme şekline, damak tadına, daha önce pişirilen yemeklerin miktarına göre aylık hammadde tahmin etmesine ve yönetmesine ve yemekleri zamana göre programlamasına yardımcı olduğunu söylemişlerdir. Dziurzanski P. ve ark. [9], çalışmalarında ticari bir mutfakta yemek pişirme planlaması ve çizelgelemesine yardımcı, kapsaml, bulut tabanlı bir uygulama geliştirmişlerdir. Tarifte yer alan bileşenlerin miktarları, pişme süreleri, enerji miktarları, pişirme bölgeleri (sıcaklığa göre gruplandırılmış pişirme bölgeleri) gibi bilgileri sisteme tanımlanır. Klasik MOEA/D (Multiobjective Evolutionary Algorithm Based on Decomposition) çok amaçlı genetik algoritmanın bir kromozomunun kodlanmasını ve özelleştirilmesini önermişlerdir. Önerilen yaklaşımın uygulanabilirliği, pişirme cihazlarının sayısı ve sipariş edilen gıda miktarına göre farklı senaryolar için deneysel olarak değerlendirilmiştir. Önerilen sistemin pişirme süresi, enerji kaybı ve gıda kalitesi arasındaki dengeleri belirlemeyi başardığını belirtmişlerdir.
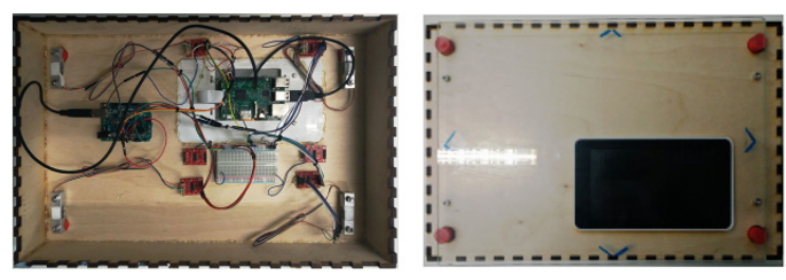

Şekil 2. Choptop'ın iç tasarımı ve üstten görünümü [7]

\subsection{Buzdolabı Temelli Sistemler}

Ferrero R. ve ark. [10], israfi azaltmak amaciyla RFID teknolojisinin akıllı bir buzdolabı cihazında gıda envanterini etkinleştirmenin bir yolu olarak kullanımını analiz ettikleri bir çalışma yapmışlardır. Buzdolabı uygulaması, Doğal Dil Etkileşimi ve ürün tanımlamayı RFID etiketleri aracılı̆̆ıyla birleştirerek, buzdolabı içeriğinin anında gözden geçirilmesini ve yakında tüketim süresinin dolacağı bir uyarıyı almanızı sağlamaktadır. Ayrıca, doğal dil aracısıyla entegre edilmiş gerçek zamanlı bir bulut veritabanının kullanılmasıyla, belirli bir ürünün evde kullanılabilirliğini otomatik olarak kontrol edilmesi veya tariflerin uygunluğunun belirlenmesi sağlanmıştır. Uygulama, Google ${ }^{\circledR}$ Assistant geliştirme çerçevesi ile entegre edilmiştir (Şekil 3) ve akıllı telefona sahip olan herkesin akıllı buzdolabı cihazıyla etkileşime girmesine izin veren akıllı bir uygulama eklentisi olarak geliştirilmiştir. Kullanıcı evde olmasa bile buzdolabına sesli asistan vasıtasıyla erişebilir. Son olarak, bu uygulama için kullanılan RFID okuyucu ve mikrodenetleyicinin yüksek bir fiyat yükü gerektirmediğini ve standart bir buzdolabına entegre edilebilir olduğunu belirtmişlerdir. Gao X. ve ark. [11], buzdolabının içindeki yiyeceklerin etkili ve doğru bir şekilde nasıl tanımlanacağı konusunu odak alarak bir çalışma gerçekleştirmişlerdir. Böylece kullanıcıların buzdolabını açmadan buzdolabındaki yiyeceklerin türünü, miktarını ve tazeliğini bilebileceğini belirtmişlerdir. YOLO, SSD, R-CNN, Fast-R-CNN ve Faster-R-CNN gibi popüler algoritmaları incelemişler, buzdolabının gerçek iç durumu ile birleştirerek, SSD (Single Shot MultiBox Detector) hedef algilama algoritmasının buzdolabının içindeki yiyecekleri tanımlamak için en uygun algoritma olduğu sonucuna varmışlardır. Optimal algoritmayı belirledikten sonra, çalışmalarinda SSD300 ve SSD512 algoritmaları tarafindan yapılan VOC2007 veri seti ile ayrıntılı bir karş1laştırma testi yapmışlardır. Deneysel sonuçta SSD512'nin buzdolabının içindeki yiyecekleri tanımlamak için daha iyi olduğu saptanmıştır. Nasir H. ve ark. [12], nesnelerin interneti ve akıllı mutfak evrimi fikrini birleştiren akı1lı buzdolabı sistemi geliştirmişlerdir. Sistem; algılama modülü, kontrol modülü ve iletim modülü olmak üzere üç ana parçadan oluşmaktadır. Alg1lama modülü yük bölmesi ve koku sensöründen oluşmakta, kontrol modülü Arduino UNO ve güç kaynağı ünitesinden oluşmakta ve son olarak, iletim modülü LCD ve Wi-Fi modülünden oluşmaktadır. Bu modüller, buzdolabının içindeki içerik durumunu belirlemek ve bir SMS veya e-posta yoluyla yiyeceğin durumu ve miktarı hakkında kullanıcıyı bilgilendirmek için birlikte çalışmaktadır. Bayya M. [13], ticari olarak satılan bir akıllı cihazın oldukça pahalı ve çalışma topluluğunun bir kısmı için bile çok erişilebilir olmadığını belirtmiştir. Bu bağlamda mevcut bir buzdolabı için geliştirilen, kural tabanlı bir algoritmaya sahip akıllı buzdolabı kavramı ele alınmıştır. Buzdolabının içini dondurucu, kapı ve raflar olmak üzere 3 bölüme ayırmış, eşyaların yerleşimini düzenleyen bir dizi özelleştirilmiş kurallar belirlemiş ve çeşitli sensörler yardımıyla içerdeki gıdaların miktar bilgisini almıştır. Sistemde kullanılan uygulama buzdolabından veri okumak için bir istek gönderir ve veriler telefona mesaj olarak gönderilir. Phuchamniphatthananun A. ve Pora W. [14], geleneksel bir ev buzdolabının donanımda yapılacak revizyonu önermişlerdir: Mevcut çevre birimleriyle geriye dönük uyumluluk sağlayan Wi-Fi özellikli bir ana kontrol kartı tasarlamışlardır. Mikrodenetleyici üzerinde, sistem verimliliğini en üst düzeye çıkarmak ve aynı zamanda gıdaların saklanma koşullarında veya kullanııının sıcaklık tercihinde sıcaklığı korumak için basit bir öğrenme algoritması da uygulanmıştır. Daha hassas sıcaklık izleme ve kontrolü için gerçek gıda sıcaklığını yansıtan bir kablosuz sensör dügümü (Wireless Sensor Node: WSN) de kullanılmıştır. Elde edilen sonuç, buzdolabının soğutma döngüsü için $\% 6,38$ ve 
buz çözme döngüsü için $\% 7,18$ ile daha yüksek verimlilik elde edebileceğini göstermiştir. Velasco J. ve ark. [15], çalışmalarında, Android uygulamasına erişerek buzdolabındaki stokları kablosuz olarak izleyebilecek bir envanter izleme oluşturmak için geleneksel bir buzdolabı, mikrodenetleyiciler ve akıllı telefonu birleştiren bir sistem sunmuşlardır. Geliştirilen buzdolabında, buzdolabının içindeki ilgili bölmelere monte edilmiş bir sensör ağ sistemi kullanılır. Her bir sensör, $\mathrm{I}^{2} \mathrm{C}$ (Inter-Integrated Circuit) iletişimleri ile birbirine bağlanan Arduino Yun ve Arduino Uno gibi mikrodenetleyicilere veri iletmektedir. Tüm veriler ve görüntüler, kullan1cıya bulut tabanlı Temboo web sitesi aracıllğıyla nesnelerin interneti uygulaması sağlamak için işlenmektedir. Temboo, Dropbox'a veri gönderme erişimine sahiptir ve tüm verilerin ve görüntülerin depolandığ bağlanılabilmektedir. Kullanıc1, Android uygulamasını kullanarak buzdolabının stoklarını veya içeriğini kablosuz olarak izleyebilmektedir. Zhang W. ve ark. [16], akıllı buzdolabı üzerine yaptıkları çalışmalarında kilo bilgisini ve çok derin öğrenme modellerini birleştiren bir meyve/sebze tanıma yaklaşımı önermişlerdir. Önerdikleri sistemde kamera ile alınan görüntüler vasıtasıyla sebze ve meyvelerin makine öğrenmesi sayesinde tanınması sağlanmıştır. Aynı zamanda ağılık sensörleriyle alınan ağırlık bilgisi derin öğrenme ile kombinlenerek çoklu kaynaklı veri birleşimi yaklaşımı önerilmiştir (Şekil 4).

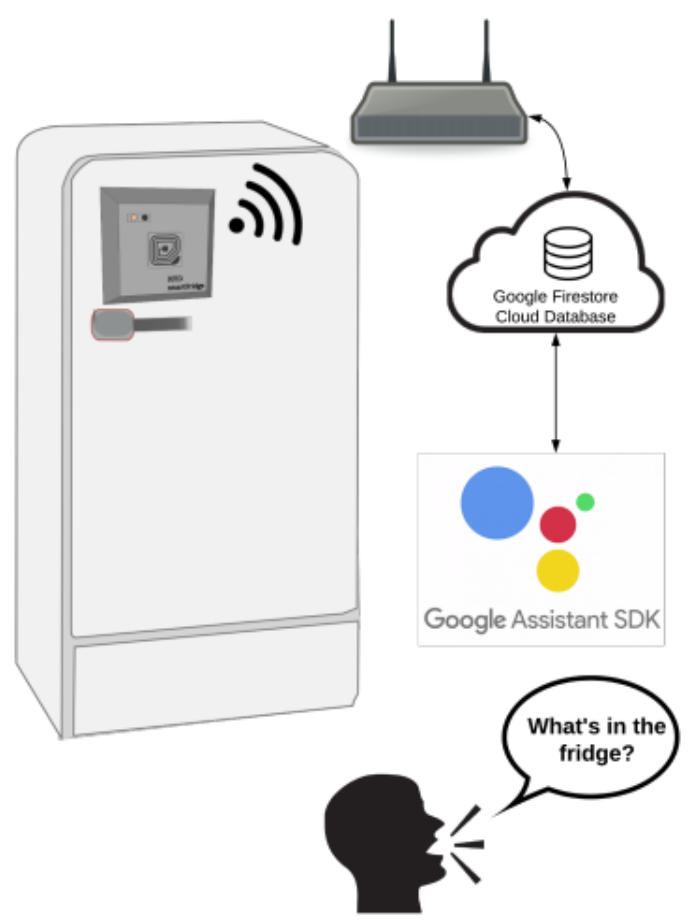

Şekil 3. Doğal dil etkileşimi ile buzdolabına erişim [10]

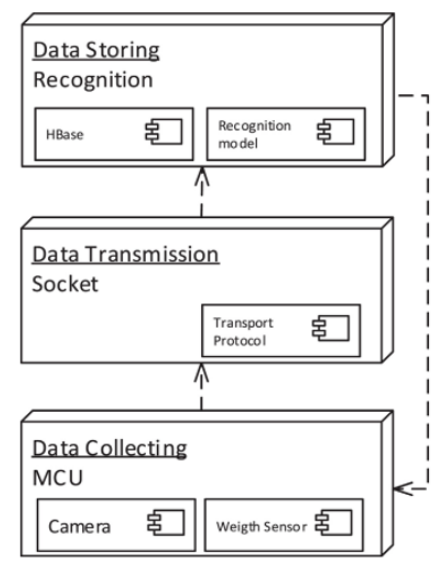

Şekil 4. Meyve/sebze tanımada çoklu kaynak yaklaşımlı sistem mimarisi [16]

\subsection{Duyusal Etkileşim Temelli Sistemler}

Schuhmacher L. ve ark. [17], çalışmalarında akıllı çevre teknolojilerinin duygusal deneyimlerle ilişkisini tanımlamışlardır. Kullanıcının duygularını artırmak için, akıllı bir mutfak ortamında bulunan global bir medya teknolojisi geliştirmişlerdir: Farklı atmosferik temalarla mutfak ambiyansını değiştirebilen dokunma ve ses kontrollü Görsel Atmosfer Uygulaması (Visual Atmosphere App: VAA). Uygulama platformuna 5 adet projektör monte edilerek görsel ve sesli temalar denenmiştir (Şekil 5). Sistem 40 adet tema içermektedir. Nicel ve nitel laboratuvar kullanıcısı çalışmalarında, VAA'nın kullanıcının duygusal durumu üzerindeki etkisini ölçmüşlerdir. Bulguları, akıllı bir ortamdaki bu yaygın medya teknolojisinin duygu geliştirme üzerinde önemli etkiye sahip olabileceğini göstermiştir. Akıllı ortam kullanıcının kişisel tercihlerine uyuyorsa bu sonuç daha da güçlüdür. $\mathrm{Bu}$ çalışmanın, akıllı çevre teknolojilerinin istenen psikolojik durumları geliştirmesine neden olan duygusal deneyimlere doğru bir adım olduğunu ifade etmişlerdir. Basharudin N. W. ve ark. [18], Alzheimer hastaları için Uyarıcı-Yanıt Uyumluluğu (Stimulus-Response Compatibility: SRC) kavramına dayalı, pişirme faaliyetlerini tamamlamaya yönlendirmek için mutfak tezgahındaki ortam ipuçlarını tasarlamaya yönelik bir çalı̧̧ma gerçekleştirmişlerdir. Aktiviteler, Hiyerarşik Görev Analizine (Hierarchical Task Analysis: HTA) dayalı pişirme faaliyetlerinin sıralı iş akışına odaklanmıştır. Tezgaha yerleştirilen kırmızı ve yeşil LED’ler ile hasta hareketlerine uyarılar verilmektedir (doğru yaptığında yeşil LED, yanlış yaptığında kırmızı LED yanarak). Wizard-of-Oz metodu, teorik akıllı ortam ipuçlarının davranışını simüle etmek için kullanılmıştır. Önerilen sistem denenmiş ve sonuçlar göstermiştir ki; mutfaktaki ortam 
ipuçlarının yardımıyla, aktivitenin ortasında kafa karışması veya aksaklık olsa bile hasta sonuna kadar görevi tamamlayabilmiştir. Ortam ipuçlarının etkinliğinin, hastanın hatalar meydana geldiğinde pişirme akışını yönlendirmenin ipuçlarını kolayca anlayabildiğini gösterdiğini belirtmişlerdir.

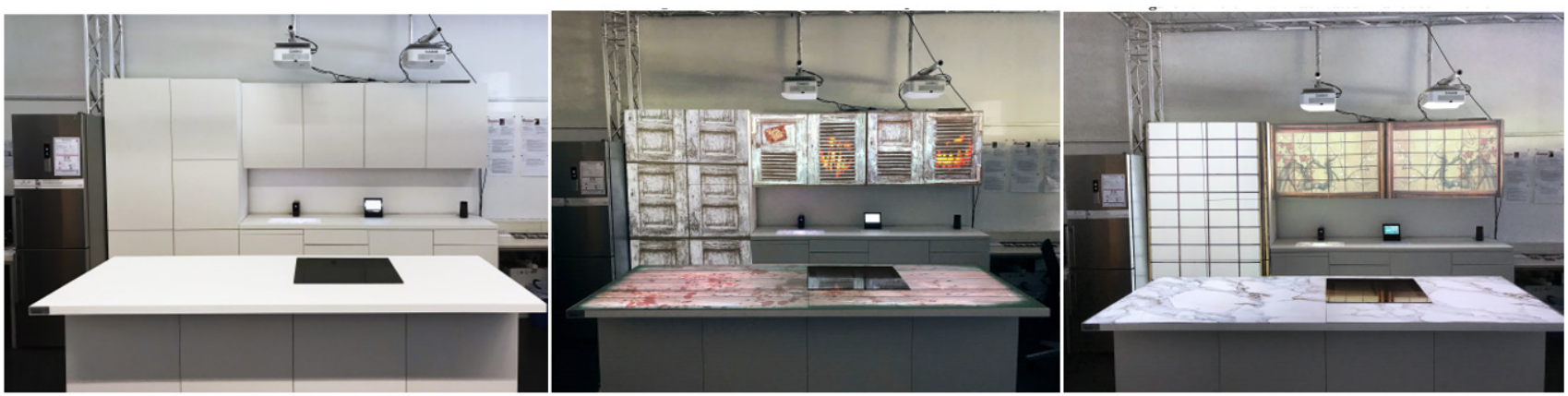

Şekil 5. Sırayla: akıllı mutfak uygulama platformu, Halloween teması, Sushi teması [17]

\subsection{Hava Ortamı Kontrol ve Yangın Önleme Temelli Sistemler}

Nugroho F. ve Pantjawati A. B. [19], nesnelerin interneti'ni kullanarak mutfak güvenlik sisteminin prototipini yapmak amacıyla bir çalışma hazırlamışlardır. Sistem; sıcaklık ve nem, alev, gaz kaçağı ve insan aktivitesi tespiti sensörleri olmak üzere 4 tip sensör ve Arduino UNO kullanılarak tasarlanmıştır. Sensör çıkışları, röleyi kontrol edecek olan Arduino'ya bağlanır. Röle, gaz kaçağı, kontrolsüz yangın ve aşırı sıcaklık artışı durumunda fan anahtarı görevi görür. Bu koşullar altında, Arduino alarmı ve LED’i de açacak ve sunucuya bilgi gönderecektir. Sonuçlar, sistemin istenen spesifikasyonlara göre çalışabileceğini göstermiştir. Castorani V. ve ark. [20], çalışmalarında mutfak hava arıtımı için akıllı bir sistemle çevresel etkiler açısından sunulan faydaları araştırmayı amaçlamışlardır. Sistem birbirine bağlı iki akıllı cihazdan oluşmaktadır: bir mutfak davlumbazı ve enerji tüketimini ve 1sı kayıplarını en aza indirgeyen, sabit bir iç mekan konforu sağlayabilen ek bir aspirasyon sistemi. Üç farklı konfigürasyon analiz edilmiş ve karşılaştırılmıştır: geleneksel aspiratör mutfak davlumbazı (A), akıllı aspiratör mutfak davlumbazı (B) ve akıllı ek aspirasyon sistemine sahip akıllı filtreleme mutfak davlumbazı (C). Her sistemin yaşam döngüsü üzerindeki çeşitli etkileri incelenmiştir. Sonuçlara göre; çevresel performans açısından en iyi çözümün $\mathrm{C}$ sistemi ancak sosyal açılardan en iyi çözümün A sistemi olduğu görülmüştür. Hsu W.L. ve ark. [21], pişirmek için bir gazlı ocak kullanıldığında, tencerede veya tavadaki yiyeceklerin veya yağın aşırı yüksek sıcaklık nedeniyle alev alabilir olduğunu belirtmişlerdir. Buna ek olarak, insanlar evden ayrılmadan önce gazlı ocağı kapatıp kapatmadıklarından emin olmayabileceklerini ve bu nedenle kontrol etmek için eve geri dönmek zorunda kalacaklarını söylemişlerdir. Bu sorunları çözmek için, çeşitli cihazlara ve işlevlere sahip bir akıllı mutfak yangın önleme sistemi geliştirdikleri bir çalışma yapmışlardır. Önerilen sistemin sahip olduğu cihaz ve işlevler şöyledir: (1) Sensörler; ocak üzerine monte edilmiştir. Alevler, yüksek sıcaklık veya gaz kaçağ1 tespit ettiklerinde, gaz beslemesini kapatmak için gaz kapatma cihazını hemen etkinleştirirler. (2) Alarm; yüksek bir ses çıkarır ve sakinleri uyarmak için yanıp söner. (3) Hat raporlama sistemi; sakinleri ve topluluk yönetim merkezini bilgilendirmek için hat mesajları gönderir ve ilgili personelin kaza ile başa çıkmak amacıyla eve girmesine izin vermek için ana giriş kapısını otomatik olarak açtırır. (4) Mutfak sakinlerinin cep telefonlarından gazlı ocağı izlemelerini sağlamak için mutfakta bir internet protokolü kamerası kuruludur. Kullanıcılar, gazlı ocağın hala açık olduğunu tespit ederse, gaz kaynağını telefonlarından kapatmak için gaz kapatma cihazını etkinleştirebilirler. Bu çalışmada geliştirilen sistemin, bir mutfak yangınından kaynaklanan kaybı etkili bir şekilde azaltabileceğini öngörmüşlerdir. Ralevski M., ve Stojkoska B. R. [22], küçük işleme birimlerini yapay zeka ve makine öğrenimi ile birleştirerek, günlük güvenliği artırmak için yeni kavram ve fikirlerin ufkunu genişletebileceklerini belirtmişlerdir. Çalışmalarında ev yangını ve gaz kaçaklarının erken tespiti için ucuz bir nesnelerin interneti tabanlı sistem tasarlamışlardır. Sıcaklığı ve gaz konsantrasyonunu ölçerek, mutfak ortamında ev yangınının artan olasılığını tespit ettikleri bir senaryoyu simüle etmişlerdir. İletişim sürecini optimize etmek ve ölçüm düğümünden sistem ağ geçidine gönderilen paket sayısını azaltmak için hareketli ortalama tahmin şemasına dayanan zaman serisi tahmin yaklaşımı uygulamışlardır. Tasarımının alt sistemi için kullandıkları donanım bileşenleri: Raspberry Pi 1 Model B, MQ5 gaz ölçüm sensörü, basit mantık seviye dönüştürücü, MCP3008 analogdan dijitale dönüştürücü şeklindedir. 


\subsection{Diğer Akıllı Mutfak Sistemleri}

Minh V.T. ve Khanna R. [23], günlük yaşamda kullanılan buzdolabı, ocak ve mikrodalga gibi mutfak aletlerinde akıllı ev otomasyon sisteminin nasıl tasarlandığ 1 ve kullanıldığını tartışmışlardır. Çalışmalarında wireless, mikrodenetleyiciler, MATLAB arayüzleri ve mutfak monitörü kullanan yeni bir mutfak otomasyon sistemi tasarımı önermişlerdir. Kontrol görevlerini yerine getirmek için Arduino Uno modülü kullanılmıştır. Bu modül sinyalleri toplar, işler ve bir zig bee ünitesi kullanarak raspberry PI modülüne kablosuz olarak gönderir. Raspberry PI, cihazların akıllı telefonlarla kontrol edildiği bir açık HAB (openHAB: Home Automation Bus) sunucusunu çalıştırır. 'Kool kitchen' adını verdikleri mobil uygulama ile de kullanıc1nın mutfakta kontrol etmek istediği altbirimi (buzdolabı, ocak, mikrodalga) kolaylıkla kontrol etmesini sağlamışlardır. Kashyap S. ve ark. [24], içindeki cihazların, mutfak tezgahlarına entegre edilen endüktif güç kaynakları (PTx: power transmitter) ile beslendiği kablosuz bir mutfak önermişlerdir. Uygulama ve PTx, yakın alan iletişimi (near-field communication: NFC) kanalı kullanarak kontrol bilgilerini değiştirmektedir. Haberleşmedeki çeşitli sorunların üstesinden gelmek için kullandıkları TCP (Transmission Control Protocol: Gönderim Kontrol Protokolü) protokolüne ek olarak kanallı algılama mekanizması önermişlerdir. Önerdikleri çözümleri kablosuz mutfak test düzeneğine uygulamış ve değerlendirmişlerdir. Bu çözümlerin sahte yeniden iletim ve paket damlalarını neredeyse tamamen ortadan kaldırdığını tespit etmişlerdir. Ayrıca, NFC zaman aralı̆̆ 1 modunda 24 kbps'de \% 53'e kadar daha düşük uçtan uca gecikme elde etmişlerdir. Swain S. ve Niyogi R. [25], akıllı ortamların, kullanıcı bağlamı ile cihaz ve hizmetlerin kullanılabilirliği açısından dinamik olduğunu belirterek bu ortamlardaki bir sorun olarak; bir hizmetin, bu tür ortamlarda kullanılamaması durumunda kullanıcının talebini karşılamak olduğunu söylemişlerdir. Bu soruna çözüm olarak çalışmalarında mevcut olmayan bir hizmete karşıllık gelen işlevsel olarak eşdeğer bir hizmet sağlayan yeni bir yöntem geliştirmişlerdir (FESC: Functionally Equivalent Service Composition: İşlevsel Olarak Eşdeğer Hizmet Bileşimi). İşlevsel olarak eşdeğer bir hizmet elde etmek için meta-akılcı ağaç kullanan bilgiye dayalı bir sistem kullanılmıştır. Yaklaşımı doğrulamak için, mevcut olmayan bir bileşeni yapısal veya işlevsel olarak eşleştiren bir bileşen öneren akıllı bir pişirme sistemi SmartChef geliştirmişlerdir.

Tablo 1'de, incelenen tüm çalışmaların kısa bir özeti sunulmuştur.
Tablo 1. Çalışma özetleri ve özellikleri

\begin{tabular}{|c|c|c|c|}
\hline Referans & Yapılan çalışma & Genel özellikler & $\begin{array}{l}\text { Teknik özel- } \\
\text { likler }\end{array}$ \\
\hline $\begin{array}{l}\text { Rezwan S. } \\
\text { ve ark. [1] }\end{array}$ & $\begin{array}{l}\text { IoT tabalı ak1llı } \\
\text { mutfak envanter } \\
\text { yönetim sistemi }\end{array}$ & $\begin{array}{l}\text { Kullanicı web veya } \\
\text { akıllı telefon ile sis- } \\
\text { tem kontrollerini sağ- } \\
\text { layabilir. }\end{array}$ & $\begin{array}{l}\text { LDR/LED ve } \\
\text { ağırlık sen- } \\
\text { sörü. } \\
\text { Arduino } \\
\text { Mega ve } \\
\text { Node MCU. }\end{array}$ \\
\hline $\begin{array}{l}\text { Buzzelli M. } \\
\text { ve ark. [2] }\end{array}$ & $\begin{array}{l}\text { YSA'ya dayalı } \\
\text { sebze/meyve ta- } \\
\text { nıma sistemi. } \\
\text { Kameralarla do- } \\
\text { natılmış buzdolabı } \\
\text { üzerinde geliştiril- } \\
\text { mesi. }\end{array}$ & $\begin{array}{l}\text { Kameralarla alınan } \\
\text { görüntüler ile ağ eği- } \\
\text { tilir ve malzemeler } \\
\text { sınıflandırılarak hi- } \\
\text { yerarşik yapı oluş- } \\
\text { turulur. }\end{array}$ & $\begin{array}{l}\text { CIFAR-10 } \\
\text { veriseti ve } \\
\text { NASnet. }\end{array}$ \\
\hline $\begin{array}{l}\text { Jian-mei S. } \\
\text { ve ark. [3] }\end{array}$ & $\begin{array}{l}\text { Ak1llı mutfak yö- } \\
\text { netim sistemi. }\end{array}$ & $\begin{array}{l}\text { IoT tabanında mut- } \\
\text { faktaki dataların top- } \\
\text { lanması, işlenmesi } \\
\text { ve uygulanması aşa- } \\
\text { maları açıklanmıştır. } \\
\text { Akıllı bir mutfak sis- } \\
\text { temi tasarımı önerile- } \\
\text { rek irdelenmiştir. }\end{array}$ & $\begin{array}{l}\text { ZigBee, web } \\
\text { server, and- } \\
\text { roid, 1şı sen- } \\
\text { sörü, insan } \\
\text { algıllama sen- } \\
\text { sörü, gaz sen- } \\
\text { sörü, duman } \\
\text { sensörü, ba- } \\
\text { sinç sensörü }\end{array}$ \\
\hline $\begin{array}{l}\text { Jarupunp- } \\
\text { hol P. ve } \\
\text { ark. [4] }\end{array}$ & $\begin{array}{l}\text { Akıllı mutfak yö- } \\
\text { netimi için mo- } \\
\text { bil uygulama ta- } \\
\text { sarımı. }\end{array}$ & $\begin{array}{l}\text { Sisteme tanımlanan } \\
\text { bileşenler mobil uy- } \\
\text { gulama ile kullanıcı } \\
\text { tarafindan kontrol } \\
\text { edilebilir. }\end{array}$ & $\begin{array}{l}\text { QR kod, } \\
\text { Android } \\
\text { Stüdyo, UML } \\
\text { ve } Z \text { şema- } \\
\text { ları. }\end{array}$ \\
\hline $\begin{array}{l}\text { Arya A. ve } \\
\text { ark. [5] }\end{array}$ & $\begin{array}{l}\text { Mutfak bileşen- } \\
\text { lerini ölçen akı1lı } \\
\text { mutfak sistemi ve } \\
\text { uygulaması. }\end{array}$ & $\begin{array}{l}\text { Işık sensörü ile alınan } \\
\text { miktar bilgisi sisteme } \\
\text { iletilir. Kullanıcı web } \\
\text { veya android ile sis- } \\
\text { teme ulaşabilir. Sis- } \\
\text { tem, seviyesi azalan } \\
\text { bileşeni sipariş ve- } \\
\text { rebilir. }\end{array}$ & $\begin{array}{l}\text { Arduino Uno } \\
\text { ve Raspberry } \\
\text { Pi, 1ş1k sen- } \\
\text { sörü, 1s1 sen- } \\
\text { sörü. }\end{array}$ \\
\hline
\end{tabular}

\begin{tabular}{|c|c|c|c|}
\hline $\begin{array}{l}\text { Sasirekha } \\
\text { S. ve ark. } \\
{[6]}\end{array}$ & $\begin{array}{l}\text { Mutfakta bulunan } \\
\text { gida maddelerine } \\
\text { uygun tarifler öne- } \\
\text { ren sistem. }\end{array}$ & $\begin{array}{l}\text { Kullanıcı web aracılı- } \\
\text { ğıyla sistemi kontrol } \\
\text { edebilir. Sistem kul- } \\
\text { lanıcıya, uygun tarif- } \\
\text { ler önerir. }\end{array}$ & $\begin{array}{l}\text { RFID, API, } \\
\text { RESTful } \\
\text { web. }\end{array}$ \\
\hline $\begin{array}{l}\text { Çelik ve } \\
\text { ark. [7] }\end{array}$ & $\begin{array}{l}\text { İnteraktif doğrama } \\
\text { tahtası: Chotop. }\end{array}$ & $\begin{array}{l}\text { Choptop adı verilen } \\
\text { doğrama tahtasında } \\
\text { tarif klavuzu, tartım } \\
\text { yapma özelliği mev- } \\
\text { cuttur. }\end{array}$ & $\begin{array}{l}\text { Yük sen- } \\
\text { sörleri, } \\
\text { Raspberry Pi }\end{array}$ \\
\hline $\begin{array}{l}\text { Sharath B. } \\
\text { ve ark. [8] }\end{array}$ & $\begin{array}{l}\text { Kullanıcı zevkine } \\
\text { göre yemek pişi- } \\
\text { ren özerk pişirme } \\
\text { sistemi. }\end{array}$ & $\begin{array}{l}\text { Tek cihaza gömülü } \\
\text { kızartma, pişirme, } \\
\text { çalkalama özellikleri } \\
\text { mevcuttur. Kullanıcı- } \\
\text { nın tek sorumluluğu, } \\
\text { malzemeleri sistem } \\
\text { tarafindan belirtilen } \\
\text { sırayla ve miktarda } \\
\text { doldurmaktır. }\end{array}$ & $\begin{array}{l}\text { DC motor- } \\
\text { lar, H-Bridge } \\
\text { sürücü, Ön- } \\
\text { görülü yapay } \\
\text { zeka algorit- } \\
\text { mas1, And- } \\
\text { roid, REST } \\
\text { server. }\end{array}$ \\
\hline
\end{tabular}




\begin{tabular}{|c|c|c|c|}
\hline Referans & Yapılan çalışma & Genel özellikler & $\begin{array}{l}\text { Teknik özel- } \\
\text { likler }\end{array}$ \\
\hline $\begin{array}{l}\text { Dziurzanski } \\
\text { P. ve ark. } \\
\text { [9] }\end{array}$ & $\begin{array}{l}\text { Ticari bir mutfakta } \\
\text { yemek pişirme } \\
\text { planlaması ve çi- } \\
\text { zelgelemesine yar- } \\
\text { dımcı uygulama. }\end{array}$ & $\begin{array}{l}\text { Bir genetik algorit- } \\
\text { manın bir kromo- } \\
\text { zomu değiştirilerek } \\
\text { yeni bir algoritma } \\
\text { üretilmiştir. Algo- } \\
\text { ritma, tarifte bulunan } \\
\text { maddelerin pişme sü- } \\
\text { relerini, pişme sıcak- } \\
\text { lıklarını, enerji mik- } \\
\text { tarları tanımlanır ve } \\
\text { ticari mutfakta pi- } \\
\text { şirme planlaması için } \\
\text { kolaylık sağlar. }\end{array}$ & MOEA/D \\
\hline $\begin{array}{l}\text { Ferrero R. } \\
\text { ve ark. [10] }\end{array}$ & $\begin{array}{l}\text { Akıllı buzdola- } \\
\text { bıyla entegre gida } \\
\text { envanteri sistemi. }\end{array}$ & $\begin{array}{l}\text { Sistem mevcut ürün- } \\
\text { lere uygun tarif ve- } \\
\text { rebilir ve son tüke- } \\
\text { tim tarihi yaklaşanlar } \\
\text { için uyarı verir. Ses } \\
\text { aracılığıyla etkileşim } \\
\text { sağlanabilen sisteme } \\
\text { kullanıcı her yerden } \\
\text { erişebilmektedir. }\end{array}$ & $\begin{array}{l}\text { RFID, Go- } \\
\text { ogle® Assis- } \\
\text { tant }\end{array}$ \\
\hline $\begin{array}{l}\text { Gao X. ve } \\
\text { ark. [11] }\end{array}$ & $\begin{array}{l}\text { Buzdolabı için- } \\
\text { deki gıdaları en iyi } \\
\text { tanımlayan algo- } \\
\text { ritma önerisi. }\end{array}$ & $\begin{array}{l}\text { YOLO, SSD, } \\
\text { R-CNN, Fast-R-CNN } \\
\text { ve Faster-R-CNN } \\
\text { gibi popüler algorit- } \\
\text { maları incelemiş ve } \\
\text { buzdolabı içindeki } \\
\text { gidaları tanımada en } \\
\text { iyi algortimanın SSD } \\
\text { olduğu tespit edil- } \\
\text { miştir. Kullanıcı mal- } \\
\text { zeme türü, miktarı ve } \\
\text { tazeliğine erişebilir. }\end{array}$ & $\begin{array}{l}\text { SSD300, } \\
\text { SSD512, VO- } \\
\text { C2007,SSD }\end{array}$ \\
\hline $\begin{array}{l}\text { Nasir H. ve } \\
\text { ark. [12] }\end{array}$ & $\begin{array}{l}\text { IoT tabanlı ak1llı } \\
\text { buzdolab1 sistemi. }\end{array}$ & $\begin{array}{l}\text { Sistemde bulunan } \\
\text { modüller sayesinde } \\
\text { buzdolabının için- } \\
\text { deki içerik durumu } \\
\text { belirlenir ve bir SMS } \\
\text { veya e-posta yoluyla } \\
\text { bilgiler kullanıcıya } \\
\text { iletilir. }\end{array}$ & $\begin{array}{l}\text { Arduino } \\
\text { UNO, LCD, } \\
\text { Wi-Fi mo- } \\
\text { dülü, gaz sen- } \\
\text { sörü, sicaklık } \\
\text { ve nem sen- } \\
\text { sörü, PLX- } \\
\text { DAQ }\end{array}$ \\
\hline $\begin{array}{l}\text { Bayya M. } \\
{[13]}\end{array}$ & $\begin{array}{l}\text { Mevcut buzdo- } \\
\text { labına uygulan- } \\
\text { mak üzere bir al- } \\
\text { goritma. }\end{array}$ & $\begin{array}{l}\text { Normal bir buzdo- } \\
\text { labına entegre edi- } \\
\text { len sensörlerle miktar } \\
\text { bilgileri alınır ve mo- } \\
\text { bil uygulama ile kul- } \\
\text { lanıcı kontrol sağlar. }\end{array}$ & $\begin{array}{l}\text { Seviye sne- } \\
\text { sörü, ağır- } \\
\text { lık sensörü, } \\
\text { RFID, Ardi- } \\
\text { uno, GSM } \\
\text { modülü. }\end{array}$ \\
\hline $\begin{array}{l}\text { Phucham- } \\
\text { niphattha- } \\
\text { nanun A. } \\
\text { ve Pora W. } \\
{[14]}\end{array}$ & $\begin{array}{l}\text { Geleneksel bir } \\
\text { buzdolabinda } \\
\text { enerji etkin bir re- } \\
\text { vizyon. }\end{array}$ & $\begin{array}{l}\text { Buzdolabına yerleşti- } \\
\text { rilen sensöler ile bil- } \\
\text { giler alınır ve denet- } \\
\text { leyiciye gönderilir. } \\
\text { Kullanıcı sıcaklık ter- } \\
\text { cihi yapabilmektedir. }\end{array}$ & $\begin{array}{l}\text { Sicaklık sen- } \\
\text { sörü, açık } \\
\text { kap1 sensörü, } \\
\text { enerji ölçüm } \\
\text { sensörü, wi- } \\
\text { reless gida s1- } \\
\text { caklığı sen- } \\
\text { sörü, WSN. }\end{array}$ \\
\hline
\end{tabular}

\begin{tabular}{|c|c|c|c|}
\hline Referans & Yapılan çalışma & Genel özellikler & $\begin{array}{l}\text { Teknik özel- } \\
\text { likler }\end{array}$ \\
\hline $\begin{array}{l}\text { Velasco J. } \\
\text { ve ark. [15] }\end{array}$ & $\begin{array}{l}\text { Buzdolab1 envan- } \\
\text { ter izleme sistemi. }\end{array}$ & $\begin{array}{l}\text { Buzdolabından sen- } \\
\text { sörler aracıllı̆ıyla } \\
\text { kablosuz şekilde alı- } \\
\text { nan bilgiler kullanıcı } \\
\text { tarafından android } \\
\text { uygulama ile takip } \\
\text { edilebilmektedir. }\end{array}$ & $\begin{array}{l}\text { Arduino Uno, } \\
\text { Arduino Yun, } \\
\text { Temboo, } \\
\text { Dropbox, } \\
\text { mikrodenet- } \\
\text { leyiciler. }\end{array}$ \\
\hline $\begin{array}{l}\text { Zhang W. } \\
\text { ve ark. [16] }\end{array}$ & $\begin{array}{l}\text { Çoklu kaynaklı } \\
\text { veri bileşimi ile } \\
\text { sebze meyve ta- } \\
\text { nıma sistemi. }\end{array}$ & $\begin{array}{l}\text { Kamera ile alınan gö- } \\
\text { rüntülere ek olarak } \\
\text { ağırlık bilgisi de sis- } \\
\text { teme girilerek ma- } \\
\text { kine öğrenmesi artı- } \\
\text { rılmıştır. }\end{array}$ & $\begin{array}{l}\text { Raspberry Pi, } \\
\text { TX1 }\end{array}$ \\
\hline $\begin{array}{l}\text { Schuhma- } \\
\text { cher L. ve } \\
\text { ark. [17] }\end{array}$ & $\begin{array}{l}\text { Farklı atmosferik } \\
\text { temalarla mutfak } \\
\text { ambiyansını de- } \\
\text { ğiştirebilen Görsel } \\
\text { Atmosfer Uygula- } \\
\text { ması. }\end{array}$ & $\begin{array}{l}\text { Kullanıcı, ses ve do- } \\
\text { kunma arayüzleri ile } \\
\text { sistemle etkileşim } \\
\text { sağlayarak mutfak te- } \\
\text { masını seçerek am- } \\
\text { biyansı değiştirebil- } \\
\text { mektedir. }\end{array}$ & $\begin{array}{l}\text { Projektör, } \\
\text { meSchup, } \\
\text { SAR Module }\end{array}$ \\
\hline $\begin{array}{l}\text { Basharudin } \\
\text { N. W. ve } \\
\text { ark. [18] }\end{array}$ & $\begin{array}{l}\text { Alzheimer has- } \\
\text { taları için ortam } \\
\text { ipuçlarını tasarla- } \\
\text { yan bir mutfak sis- } \\
\text { temi. }\end{array}$ & $\begin{array}{l}\text { Uyarıcı yanıt uyum- } \\
\text { luluğu kullanılarak } \\
\text { hiyerarşik iş akışı ta- } \\
\text { banlı bir pişirme sis- } \\
\text { temi geliştirilmiştir. } \\
\text { Hastalar tarifi yapar- } \\
\text { ken adım adım iz- } \\
\text { lenerek yönlendiril- } \\
\text { mektedir. }\end{array}$ & $\begin{array}{l}\text { SRC, HTA, } \\
\text { LED. }\end{array}$ \\
\hline $\begin{array}{l}\text { Nugroho } \\
\text { F. ve Pant- } \\
\text { jawati A. B. } \\
{[19]}\end{array}$ & $\begin{array}{l}\text { Mutfak güvenlik } \\
\text { sisteminin IoT ta- } \\
\text { banlı prototipi. }\end{array}$ & $\begin{array}{l}\text { Sensörler ile algıla- } \\
\text { nan olağandışı du- } \\
\text { rumlarda sisteme } \\
\text { bilgi gider ve sistem } \\
\text { gerekli güvenlik ön- } \\
\text { lemini alarak kullanı- } \\
\text { c1ya bilgi gönderir. }\end{array}$ & $\begin{array}{l}\text { Sicaklık ve } \\
\text { nem sensörü, } \\
\text { alev sen- } \\
\text { sörü, gaz ka- } \\
\text { çağ1 sensörü, } \\
\text { insan akti- } \\
\text { vitesi tespit } \\
\text { sensörü, Ar- } \\
\text { duino IDE, } \\
\text { ESP 8266-01, } \\
\text { Alarm, Led }\end{array}$ \\
\hline $\begin{array}{l}\text { Castorani } \\
\text { V. ve ark. } \\
{[20]}\end{array}$ & $\begin{array}{l}\text { Mutfak hava arı- } \\
\text { tımı için akıllı bir } \\
\text { sistem. }\end{array}$ & $\begin{array}{l}\text { Geleneksel aspiratör } \\
\text { ile ek aspirasyon sis- } \\
\text { temi karşılaştırılarak } \\
\text { çevresel performans } \\
\text { ve sosyal açılardan } \\
\text { değerlendirilip kıyas- } \\
\text { lanmıştır. }\end{array}$ & $\begin{array}{l}\text { Aspiratör, } \\
\text { ototmatik } \\
\text { veya manuel } \\
\text { kontrol edile- } \\
\text { bilen ek aspi- } \\
\text { rasyon siste- } \\
\text { min. }\end{array}$ \\
\hline
\end{tabular}




\begin{tabular}{|c|c|c|c|}
\hline Referans & Yapılan çalışma & Genel özellikler & $\begin{array}{l}\text { Teknik özel- } \\
\text { likler }\end{array}$ \\
\hline $\begin{array}{l}\text { Hsu W.L. } \\
\text { ve ark. [21] }\end{array}$ & $\begin{array}{l}\text { Akıllı mutfak yan- } \\
\text { gın önleme siste- } \\
\text { min. }\end{array}$ & $\begin{array}{l}\text { Sistemdeki cihaz ve } \\
\text { işlevler vasıtasıyla } \\
\text { mutfakta meydana } \\
\text { gelen yangın, gaz ka- } \\
\text { çağı gibi durumlar } \\
\text { bildirilir ve önlem } \\
\text { alınır. }\end{array}$ & $\begin{array}{l}\text { Alev sen- } \\
\text { sörü, sıcak- } \\
\text { lık ve gaz ka- } \\
\text { çağ1 sensörü, } \\
\text { alarm, hat ra- } \\
\text { porlama sis- } \\
\text { temi, IP } \\
\text { kamera, Ar- } \\
\text { duino Uno, } \\
\text { Webduino } \\
\end{array}$ \\
\hline $\begin{array}{l}\text { Ralevski } \\
\text { M., ve Stoj- } \\
\text { koska B. R. } \\
{[22]}\end{array}$ & $\begin{array}{l}\text { Ev yangını ve gaz } \\
\text { kaçağı erken tes- } \\
\text { piti sistemi. }\end{array}$ & $\begin{array}{l}\text { IoT'den yararlanıla- } \\
\text { rak sıcaklık ve gaz } \\
\text { konsantrasyonu öl- } \\
\text { çülerek, mutfak orta- } \\
\text { mında ev yangınının } \\
\text { artan olasılığı tes- } \\
\text { pit edilerek bir senar- } \\
\text { yoyu simüle edilir. }\end{array}$ & $\begin{array}{l}\text { Raspberry Pi } \\
1 \text { Model B, } \\
\text { MQ5 gaz öl- } \\
\text { çüm sensörü, } \\
\text { basit man- } \\
\text { tık seviye dö- } \\
\text { nüştürücü, } \\
\text { MCP3008. }\end{array}$ \\
\hline $\begin{array}{l}\text { Minh V.T. } \\
\text { ve Khanna } \\
\text { R. [23] }\end{array}$ & $\begin{array}{l}\text { Günlük yaşamda } \\
\text { kullanılan mutfak } \\
\text { aletlerinde akıllı } \\
\text { ev otomasyon sis- } \\
\text { teminin nasıl ta- } \\
\text { sarlandığı ve kul- } \\
\text { lanıldığ ile ilgili } \\
\text { çalışma. }\end{array}$ & $\begin{array}{l}\text { Çeşitli tasarımlarla } \\
\text { yeni bir mutfak oto- } \\
\text { masyon sistemi ta- } \\
\text { sarlanmıştır. Ayrıca } \\
\text { geliştirilen mobil uy- } \\
\text { gulama ile kullanıcı } \\
\text { mutfakta bulunan is- } \\
\text { tediği aleti kontrol } \\
\text { edebilmektedir. }\end{array}$ & $\begin{array}{l}\text { MATLAB, } \\
\text { Arduino Uno, } \\
\text { Raspberry PI, } \\
\text { openHAB, } \\
\text { Arduino, zig } \\
\text { bee }\end{array}$ \\
\hline $\begin{array}{l}\text { Kashyap S. } \\
\text { ve ark. [24] }\end{array}$ & $\begin{array}{l}\text { Kablosuz mutfak } \\
\text { uygulamas1. }\end{array}$ & $\begin{array}{l}\text { Endüktif güç kaynak- } \\
\text { ları ile beslenen mut- } \\
\text { fak cihazlarının ya- } \\
\text { kın alan etkileşimi ile } \\
\text { kontrolü sağlanmak- } \\
\text { tadır. }\end{array}$ & $\begin{array}{l}\text { TCP, PTx, } \\
\text { NFC }\end{array}$ \\
\hline $\begin{array}{l}\text { Swain S. ve } \\
\text { Niyogi R. } \\
{[25]}\end{array}$ & $\begin{array}{l}\text { Mevcut olmayan } \\
\text { bir hizmete karş1- } \\
\text { lik gelen, işlevsel } \\
\text { olarak eşdeğer bir } \\
\text { hizmet sağlayan } \\
\text { yöntem (FESC). }\end{array}$ & $\begin{array}{l}\text { Önerilen yöntem } \\
\text { SmartChef adı veri- } \\
\text { len akıllı pişirme sis- } \\
\text { temi üzerinde gerçek- } \\
\text { leştirilmiştir. Yemek } \\
\text { tarifinde bulunma- } \\
\text { yan malzemeye alter- } \\
\text { natif malzeme öneren } \\
\text { bir algoritma gelişti- } \\
\text { rilmiştir. }\end{array}$ & $\begin{array}{l}\text { Meta-akılc1 } \\
\text { ağaç algorit- } \\
\text { ması. }\end{array}$ \\
\hline
\end{tabular}

\section{TARTIŞMA ve SONUÇ}

$\mathrm{Bu}$ makalede, akıllı sistemler çerçevesinde bir mutfağın gereksinimleri göz önüne alınarak yapılmış veya önerilmiş akıllı mutfak sistemleri incelenmiştir. Son yıllarda yapılan bu güncel çalışmalar, tasarlanış amacına göre bazı alt başlıklar altında sınıflandırılmıştır. Bu sınıflar: mutfaktaki malzemelerin yönetilebildiği envanter sistemi öneren çalışmalar; yemek pişirme önerisi, planı veya direktifi verebilen sistemler; sadece buzdolabına entegre edilen, gıda maddelerinin tür ve miktar bilgisinin alındığı, sıcaklık ayarının yapılabildiği akıllı sistemler; kullanıcıyla direk duyusal etkileşim kurarak kontrol sağlayan sistemler; mutfaktaki hava ortamını kontrol ederek yangın ve gaz kaçağı tespiti yapan veya optimum hava ortamını sağlayan sistemler; mutfaktaki akıllı sistemleri yönetmek için çeşitli haberleşme, öğrenme ve kontrol algoritmaları öneren çalışmalar şeklinde sıralanabilir. İncelenen çalışmaların benzeri birçok çalışma literatürde mevcuttur. Ayrıca çeşitli firmaların ticari olarak sunduğu akıllı mutfak veya buzdolabı sistemleri de mevcuttur.

Yapılan çalışmalarda da görüldüğü gibi akıllı bir sistemin temelinde insan konforu yatmaktadır. İnsan konforunun, zamanın hızla aktığı ve kadın erkek tüm bireylerin iş hayatında yer aldığ 1 günümüzde zamandan tasarruf ve hayatı kolaylaştıracak çözümler getirmesi beklenmektedir. Güncel çalışmalar bu beklentileri karşılamaya yönelik uygulanabilir birçok yenilik sunmaktadır. Akıllı mutfak sistemleri, evin ve hayatımızın en önemli mekanlarından biri olan mutfaktaki işleri kolaylaştırmada, zamandan tasarruf sağlamada, israfin önüne geçmede, güvenlik gerektiren durumlar için tedbir almada ve hatta sağlik problemleri sebebiyle yardıma ihtiyaç duyan bireylere yardımcı olmada oldukça önemli ve gerekli sistemlerdir. Bu sistemler sayesinde enerjiden tasarruf sağlanabilmekte aynı zamanda günlük hayat daha da kolaylaşıp konfor sağlanabilmektedir. Enerji kaynaklarının hızla tükenmekte olduğu günümüz dünyasında enerjiyi etkin kullanmak oldukça önemli olup, her alanda dikkat edilmesi gereken bir husus olmuştur. Enerjiden tasarruf sağlamak kullanıcı konforunu yok saymak anlamına gelmemektedir. İyi bir tasarımla her açıdan uygun ve avantajlı bir sistem oluşturmak mümkündür. Daha birçok yeni senaryo geliştirilerek bu makalede incelenen çalışmaları ileri taşıyacak yeni sistemler tasarlanabilir.

\section{KAYNAKÇA}

[1] Rezwan S., Ahmed W., Alam Mahia M. ve Rezaul Islam M. (2018), IoT Based Smart Inventory Management System for Kitchen Using Weight Sensors, LDR, LED, Arduino Mega and NodeMCU (ESP8266) Wi-Fi Module with Website and App, 4th International Conference on Advances in Computing, Communication and Automation, ICACCA, Doi: 10.1109/ICACCAF.2018.877.6761.

[2] Buzzelli M., Belotti F. ve Schettini R. (2018), Recognition of Edible Vegetables and Fruits for Smart Home Appliances, IEEE 8th International Conference on Consumer Electronics, Doi:10.1109/ICCE-Berlin.2018.857.6236

[3] Jian-Mei, S., Li-Juan W., Xi Y. ve Jun-Shan Y. (2018), Design and Implementation of Intelligent Kitchen System Based on Internet of Things. 2018 International Conference on Smart 
Grid and Electrical Automation (ICSGEA). doi:10.1109/icsgea.2018.00070

[4] Jarupunphol P., Buathong W., Chansaeng T., ve Laosen N. (2018). A descriptive design for a smart kitchen management application (SKM). 2018 International Conference on Information and Computer Technologies (ICICT). doi:10.1109/infoct.2018.835.6841

[5] Arya A., Taliyan A., Chauhan P., ve Gautam A. (2019). Smart Kitchen with New Measurement, Web and Application Based with Affordable Design. 2019 4th International Conference on Internet of Things: Smart Innovation and Usages (IoTSIU). doi:10.1109/iot-siu.2019.877.7488

[6] Sasirekha S., Louis Paul I.J. ve Swamynathan S. (2018), An API Centric Smart Kitchen Application, 2nd International Conference on Computer, Communication, and Signal Processing (ICCCSP 2018), Doi:10.1109/ICCCSP.2018.845.2850

[7] Celik T., Gardine R., Lukács-Kisbandi O., Parker G., Partridge S. ve Bennett P. (2018), Choptop: An Interactive Chopping Board, Human Factors in Computing Systems. :1-6, Doi: 10.1145/3170.427.3188486

[8] Sharath B.S., Srisha R., Shashidhar K.V., ve Bharadwaj S.S. (2018). Intelligent and Smart Cloud Based Autonomous Robotic Kitchen System. 2018 Second International Conference on Intelligent Computing and Control Systems (ICICCS). doi:10.1109/iccons.2018.866.3208.

[9] Dziurzanski P., Zhao S. ve Indrusiak L.S. (2019). Integrated Process Planning and Scheduling in Commercial Smart Kitchens. Computer Science.

[10] Ferrero R., Vakili M. G., Giusto E., Guerrera M., ve Randazzo V. (2019). Ubiquitous Fridge With Natural Language İnteraction. 2019 IEEE International Conference on RFID Technology and Applications (RFID-TA). doi:10.1109/ rfid-ta.2019.889.2025

[11] Gao X., Ding X., Hou R. ve Tao Y. (2019), Research on Food Recognition of Smart Refrigerator Based on SSD Target Detection Algorithm. Association for Computing Machinery (ACM), ISBN 978-1-4503-7150-6/19/07.

[12] Nasir H., Wan Aziz W.B., Kadir K. ve Khan S. (2018), The Implementation of IoT based Smart Refrigerator System. 2nd International Conference on Smart Sensors and Application (ICSSA), Doi: 10.1109/ICSSA.2018.853.5867.

[13] Bayya M. (2019), Low cost Smart Refrigerator. 2019 IEEE Region 10 Conference (TENCON 2019), doi:10.1109/TENCON.2019.892.9291.

[14] Phuchamniphatthananun A. ve Pora W. (2019), A Smart Domestic Refrigerator with Energy Efficiency Improvement. 2019 IEEE Asia Pacific Conference on Circuits and Systems (APCCAS), doi: 10.1109/APCCAS47518.2019.895.3072.

[15] Velasco J., Alberto L., Ambatali H.D., Canilang M, Daria V., Liwanag J.B., Madrigal G.A (2020), Internet of Things-Based
(Iot) Inventory Monitoring Refrigerator Using Arduino Sensor Network. Indonesian Journal of Electrical Engineering and Computer Science, Vol. 18, No. 1, April 2020, pp. 508515.

[16] Zhang W., Zhang Y., Zhai J, Zhao D., Xu L., Zhou J., Li Z., Yang S. (2018), Multi-Source Data Fusion Using Deep Learning for Smart Refrigerators. Computers in Industry, 95, $15-21$.

[17] Schuhmacher L., Pagenkopf A., Lingamaneni R. ve Scheible J. (2018), Emotion Enhancement through Ubiquitous Media Technology in a Smart Kitchen Environment, Mobile and Ubiquitous Multimedia, 317-325 Doi: $10.1145 / 3282.894 .3282904$.

[18] Basharudin N. W., Ku Azir K. N. F., Khairuddin A. M., ve Ehkan P. (2019). Ambient Cues of Kitchen Counter in Guiding Cooking Activities for Alzheimer's Patient. 2019 IEEE International Conference on Pervasive Computing and Communications Workshops (PerCom Workshops). doi:10.1109/percomw.2019.873.0829

[19] Nugroho F. ve Pantjawati A. B. (2018), Automation and Monitoring Smart Kitchen Based on Internet of Things (IoT), IOP Conference Series: Materials Science and Engineering, Doi: 10.1088/1757-899X/384/1/012007.

[20] Castorani V., Rossi M., Germani M., Mandolini M ve Vita A. (2018), Life Cycle Assessment of Home Smart Objects: Kitchen Hood Cases, 25th CIRP Life Cycle Engineering (LCE) Conference, 69:499-504, Doi: 10.1016/j.procir.2017.11.113

[21] Hsu W.-L., Jhuang J.-Y., Huang C.-S., Liang C.-K., ve Shiau Y.-C. (2019). Application of Internet of Things in a Kitchen Fire Prevention System. Applied Sciences, 9(17), 3520. doi:10.3390/app9173520

[22] Ralevski M., ve Stojkoska B. R. (2019). IoT based system for detection of gas leakage and house fire in smart kitchen environments. 2019 27th Telecommunications Forum (TELFOR). doi:10.1109/telfor48224.2019.897.1021

[23] Minh V.T. ve Khanna R. (2018), Application of Artificial Intelligence in Smart Kitchen, International Journal of Innovative Technology and Interdisciplinary Sciences. Vol 1, Iss 1, Pp 1-8. Doi:https://doi.org/10.15157/IJITIS.2018.1.1.1-8.

[24] Kashyap S., Rao V.S., Prasad V. ve Staring T. (2018), Cook over IP: Adapting TCP for Cordless Kitchen Appliances, IEEE/ACM Third International Conference on Internet-of-Things Design and Implementation, Doi: 10.1109/IoTDI.2018.00011

[25] Swain, S. ve Niyogi, R. (2020), FESC: Functionally Equivalent Service Composition. Internet of Things, 100151. doi:10.1016/j.iot.2019.100151. 